\title{
Treatment of A Traumatic Injury of Hand With Persian Medicine
}

\section{Hoorieh Mohammadi Kenari ${ }^{1}$, Gholamreza Kordafshari², Somayeh Aghighi $^{3}$, Maryam Moghimi $^{2 *}$}

${ }^{1}$ Research Institute for Islamic and Complementary Medicine, School of Persian Medicine, Iran University of Medical Sciences, Tehran, Iran

${ }^{2}$ School of Persian Medicine, Tehran University of Medical Sciences, Tehran, Iran

${ }^{3}$ School of Unani Medicine, Hamdard University, New Delhi, India

*Corresponding Author: Maryam Moghimi, School of Persian Medicine, Tehran University of Medical Sciences, Tehran, Iran Tel: +989125135631; E-mail: mmoghimi60@yahoo.com

Received: 19 March 2018; Accepted: 26 March 2018; Published: 28 March 2018

\begin{abstract}
Introduction: Trauma and its complications are one of the most important causes of workforce disability in the community. Therefore, for the more effective treatment of traumatic complications, the use of traditional and complementary medicine capacities along with conventional medicine seems to be necessary
\end{abstract}

Case Report: The patient was a 44-year-old man under the care of conventional medicine due to a trauma of the right hand. But the treatment was not successful, and eventually the patient was a candidate for amputating four right fingers. Fortunately, therapeutic measures and leech therapy in Persian medicine prevented the fingers from amputation and returned the normal function of the hand to the patient.

Conclusion: Persian medicine was successful in treating the patient with a nutritional modification, body reinforcement, body cleansing of waste materials, local clearance of the site of injury, and preventing the reaccumulation of waste materials at the site of injury, along with the early therapies of conventional medicine.

Keywords: Hand; Traumatic Injury; Persian Medicine 


\section{Introduction}

The three main and common causes of trauma are as follows: car accidents, Fire and falling. Many injuries that do not lead to death reduce quality of life and cost a lot to cure. Half of these injuries occur in under $45 \mathrm{~s}$. Since a high percentage of these people are part of the community workforce, returning to work after an incident is one of the main concerns of the community [1]. Therefore, therapeutic planning is important in this regard and the use of complementary medicine in addition to conventional medicine, in order to reduce costs and increase the effectiveness of treatment, prevent surgery or amputation, and reduce the social damage resulting from accidents and traumas, seems to be necessary.

Persian medicine (PM) is a widespread and rooted science based on temperament and quadruple humors (blood, yellow bile, phlegm and black bile) that has been preserved from great physicians and scientists such as Razes and Avicenna. The change in temperament and the quality and quantity of these humors is the basis of disease in PM and temperament adjustment is the main principle of treatment [2]. In this article, a traumatic injury of hand is presented with finger amputation plan of treatment in conventional medicine, which the amputation was prevented by using PM treatment.

\section{Case Report}

The patient was a 44 years old man admitted to the hospital with traumatic injury of right hand due to a car accident. In the primary radiography of the right hand, fractures in the middle and distal phalanxes of third, fourth and fifth fingers, with the destruction of the joints of that fingers, were evident. During the period of hospitalization, the patient underwent three orthopedic surgeries and vascular transplantation on the right hand. 17 days after admission, doctors decided to amputate the second to fifth fingers because of the failure of the treatment. The patient did not consent to amputation and was discharged from the hospital at his request and referred to the Persian medicine clinic.

The patient was a weak thin man who seemed pale. At the time of first visit vital signs were normal and the condition of his right hand was as follows: The first finger was apparently healthy with skin scratches. The second finger had swelling and edema, and the internal part had a lesion and sutured. The third finger had swelling, redness and discharges. The lateral part of the second and third phalanxes was without skin and had a deep sutured lesion with pussy discharge. The lateral part of all phalangeal bones of fourth finger was skinless and had a deep lesion. The end of the first phalanx and the lateral part of the second phalanx of the fifth finger also had a deep wound with pussy discharge. The radial pulse of patient's right hand was slightly weaker than the left, and the rest of the upper extremity had no problem. Past medical history was negative.

The first plan for the patient was debridement of necrotic tissues. The wound was then washed with a mixture of thyme (Zataria multiflora), chamomile (Matricaria chamomilla) and pennyroyal (Mentha pulegium) distillates. The patient was then advised to steam cabbage (Brassica oleracea), spinach (Spinacia oleracea) and marshmallow (Althaea officinalis) flower, then mix it with butter and put it on the wounds as a poultice. 
The patient was advised to avoid eating eggplant, lentils, cocoa, coffee, fast food, industrial food such as compote and canned food, industrial Juice, soda and ice.

The patient was recommended to use the following foods in the daily diet:

- 15 raw peeled Almond (Prunus dulcis) a day.

- 20 Currant (Vitis vinifera) a day.

- A peeled grated ripe apple mixed with a teaspoonful of honey, a tablespoonful of rose (Rosa damascena) water and a little saffron (Crocus sativus) twice a day.

Oral medication prescribed to the patient was:

- A decoction of teaspoonful of each of thyme (Zataria multiflora), pennyroyal (Mentha pulegium), marjoram (Origanum vulgare) and cuscute (Cuscuta epithymum) 3 times a day.

In the second visit, which was performed 24 hours after the first one, in addition to the above mentioned, the following drugs were prescribed to the patient:

- Aloe Vera capsule, daily.

- Anointing the wounds with St. John's wort (Hypericum perfpratum) oil and then cover the wounds by Aloe Vera cream.

Also leech therapy was included in the daily therapeutical protocol of patient for 10 days.

By taking the medications, the patient's physical condition gradually improved; his weight increased slightly and the paleness was resolved. During the first 3-4 days of treatment by (Figure 1), the edema of the fingers and back of the hand significantly decreased and the wounds improved. The movements of the fingers improved greatly after two weeks. Ligaments, nerves, muscles and skin of the hand were gradually restored within a month. Finally, healing progressed to a degree that not only amputation was prevented, but also the right hand function is normal at the moment. The only treatment currently used by the patient is anointing of fresh skin with almond oil to prevent skin dryness.

\section{Discussion and conclusion}

In this case, conventional medicine measures were not able to treat the disease and repair damaged tissues, so amputation was suggested as the only solution to the patient. But Persian medicine performed another therapeutic approach.

From the PM point of view, when an organ suffers from a trauma, it becomes weak and all the waste materials in the body rush towards it. Therefore, the removal of waste from the organ is an essential component. But when there is weakness in the body, the response to treatment is not desirable. So, as well as eliminating waste materials and correcting the temperament of organ, the body should be strengthened [3-8]. In this patient, the therapeutic approach was to improve nutrition, local and general cleansing of the body from waste and strengthen it to fight the disease. 
The first treatment after debridement was to wash the wounds with a mixture of thyme (Zataria multiflora), chamomile (Matricaria chamomilla) and pennyroyal (Mentha pulegium) distillates. Based on the PM resources, thyme (Zataria multiflora) removes waste from the ducts and pores of organ and disinfects it. Chamomile also has anti-toxic effects in addition to eradicating and eliminating waste, and according to the unique properties mentioned in PM books about this plant, it prevents the re-accumulation of garbage at the site of the damage. Pennyroyal (Mentha pulegium) also has strong anti-toxic effects [3-5, 9-11]. In recent studies, the anti-inflammatory and antibacterial effects of these plants have been proven. It has been shown that thyme essential oil enhances innate immunity and can be used to prevent and treat diseases and to stimulate and strengthen the immune system. In addition, the injection of aqueous extract and topical rubbing of various thyme plants have anti-inflammatory effects, which can be due to the effect on opioid receptors [12-13]. In another study, the antibacterial effects of pennyroyal (Mentha pulegium) were studied. During this study, it was found that pennyroyal oil has very strong antibacterial properties. In addition, the anti-microbial effects of pennyroyal on Listeria monocytogenes, Klebsiella pneumonia, fungi and yeasts, and also anti-inflammatory and antipyretic effects of which have been proven [14]. As mentioned, drinking the decoction of thyme and pennyroyal was also prescribed to the patient.

After washing the wounds, a poultice composed of steamed cabbage (Brassica oleracea), spinach (Spinacia oleracea), marshmallow (Althaea officinalis) flower and butter was put on them. In the PM point of view, cabbage changes the consistency of waste material and prepares them for disposal. Topical use is also recommended for removing swelling and wound healing. Spinach, in addition to cleaning up wastes, prevents its re-accumulation at the site of injury. Marshmallow flower has similar characteristics and in PM books it has been emphasized on its topical use for healing wounds and relieving swellings, lesions and fractures [3-5, 9-11].

In the conventional medicine articles, there is some evidences of positive effect of these plants on the wounds. A study in Brazil in 2013 found that an ointment made from the cabbage extract, accelerated wound healing by mechanism of increasing collagen type 1 fibers [15]. In the case of marshmallow, its effects on increasing the gene expression associated with specific cell adhesion proteins, growth regulators, extracellular matrix, cytokine release and apoptosis have been proven. The aqueous extract and polysaccharides of marshmallow are potent amplifiers of cellular physiology and epithelial cells, and this proves the therapeutic use of it in the treatment of stimulated tissues and tissue repair [16].

On the other hand, it was important to modify the patient's diet, so dietary recommendations were considered for the patient. Based on the PM resources, all of foods the patient advised to avoid, increase garbage and waste material in the body and disrupt the normal process of improving damage and weakens the body's immune system. On the contrary, eating currants, almonds, apples, saffron and rose water will strengthen the body - especially 3 main organs (heart, brain and liver) and increase the body's ability to fight the pathogens [3-11].

From the perspective of conventional medicine, eating apple with its antioxidant effect accelerates the repair of epithelial cells [17]. Saffron (Crocus sativus) has an anti-inflammatory effect and has a role in strengthening the 
immune system and regulating the function of $\mathrm{T}$ cells [18-19]. Rose (Rosa damascena) products, including rose water, also boost the immune system [20].

In medications administered orally, in addition to thyme and pennyroyal, oregano (Origanum vulgare) and cuscute (Cuscuta epithymum) were also used. In PM books, it is stated that marjoram can dilute thick and sticky waste materials and remove them from the surface and pores of the organs [3-5, 9-11]. In recent studies, the antiinflammatory effects of marjoram on the basis of cytokine response have been investigated on T-helper1 macrophages. Based on the results, marjoram reduces inflammatory cytokines such as TNF- $\alpha$, IL-1 $\beta$, IL- 6 and increases anti-inflammatory cytokines such as IL-10, which proves anti-inflammatory effects of this medical herb [21]. Cuscute also cleans up the waste materials and gives the patient a sense of vitality and tranquility [3-5, 9-11].

On the second day, Aloe Vera was administered topically and orally to the patient. Aloe Vera, based on the properties mentioned in the PM books, absorbs garbage, pus and waste materials from the depth of the body, excrete them from the body, and plays an important role in vascular purification and healing of late recovery wounds [3-5, 9-11]. Recent researches have shown that topical use of Aloe Vera improves the morphological, biochemical and biomechanical properties of the wound and helps repair it [22]. Recent medical articles indicate that the use of Aloe Vera cream in the surgical site has a positive effect on reducing postoperative pain and accelerates wound healing [23-25]. Aloe Vera also has significant beneficial effects in the treatment of burn wounds [26-27].

St. John's wort (Hypericum perfpratum) oil, which was prescribed for topical use, is highly recommended in PM resources for disposing the wastes and cleansing the pussy wounds [3-5, 9-11]. In recent studies, St. John's wort has been proven to be useful for wound healing, and its effect is due to increased production of collagen fibroblasts and increased activity of multifaceted fibroblastic cells, which plays an important role in wound healing and its closure. It also has antibacterial effects on gram-positive and gram-negative bacteria [28-30].

One of the most important stages of the treatment was leech therapy (Figure 2), which was done daily. Leech therapy in Persian medicine is used to remove waste materials from the affected position and is, of course, prescribed when the whole body is cleaned up [3-5, 7-8]. Therefore, in this patient, along with general cleansing drugs, leech therapy was also used to stimulate the immune system and remove the waste material from the injury position. Nowadays, as in the past, leech therapy is again used in medicine, especially in plastic and reconstructive surgery to treat intravenous congestion, which is a major threat to the surgical organ. Many plastic surgeons in the UK and Ireland use leech therapy after surgery.

In addition, leech therapy in microsurgery is used to increase intravenous circulation, especially in finger transplants or dermal flaps. In a study, medical leeches used to restore the venous circulation destroyed in the affected tissue, and in the end, the result was that there are occasions where there is sufficient arterial circulation and insufficient venous circulation. In these cases, medical leeches play a very important role in rescuing the damaged tissue [31]. In another study in the UK, a finger that had been exposed to the gangrene after four days of closure by the tourniquet, was rescued by leech therapy [32]. 
Finally, injured fingers were saved and improved by using PM medications (Figure 3).

PM was successful in treating the patient with a nutritional modification, body reinforcement, body cleansing of waste materials, local clearance of the site of injury, and preventing the re-accumulation of waste materials at the site of injury, along with the early therapies of conventional medicine. It is hoped that this Case Report will pave the way for wider and more extensive research on the treatment of traumatic complications by Persian medicine.

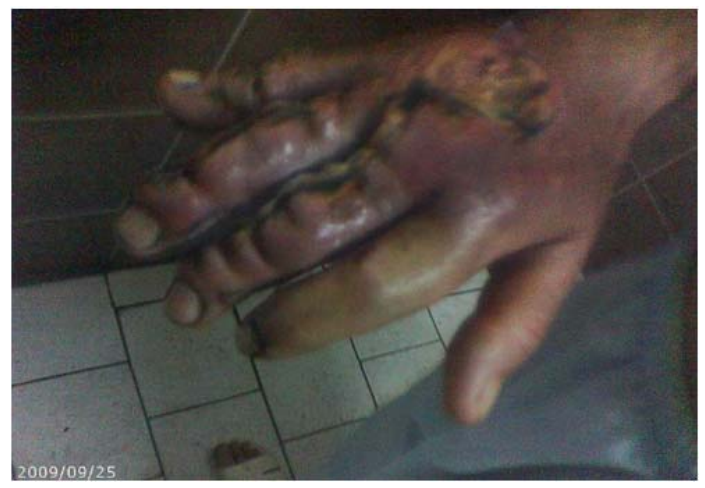

Figure 1: The hand picture of patient at the first visit of Persian medicine

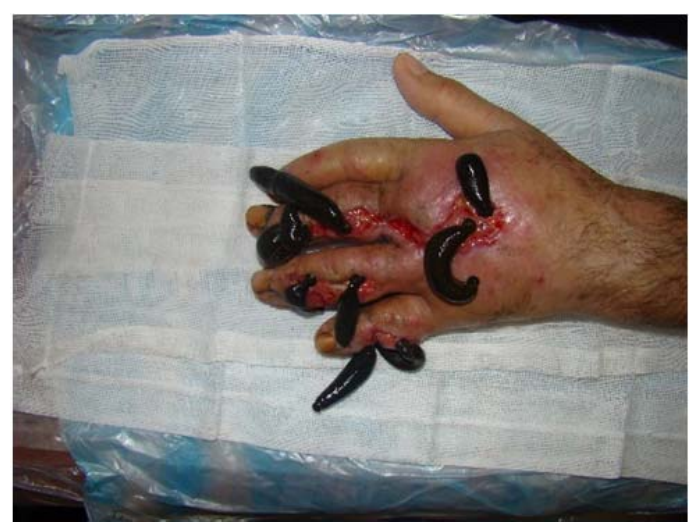

Figure 2: Leech therapy of the injured hand
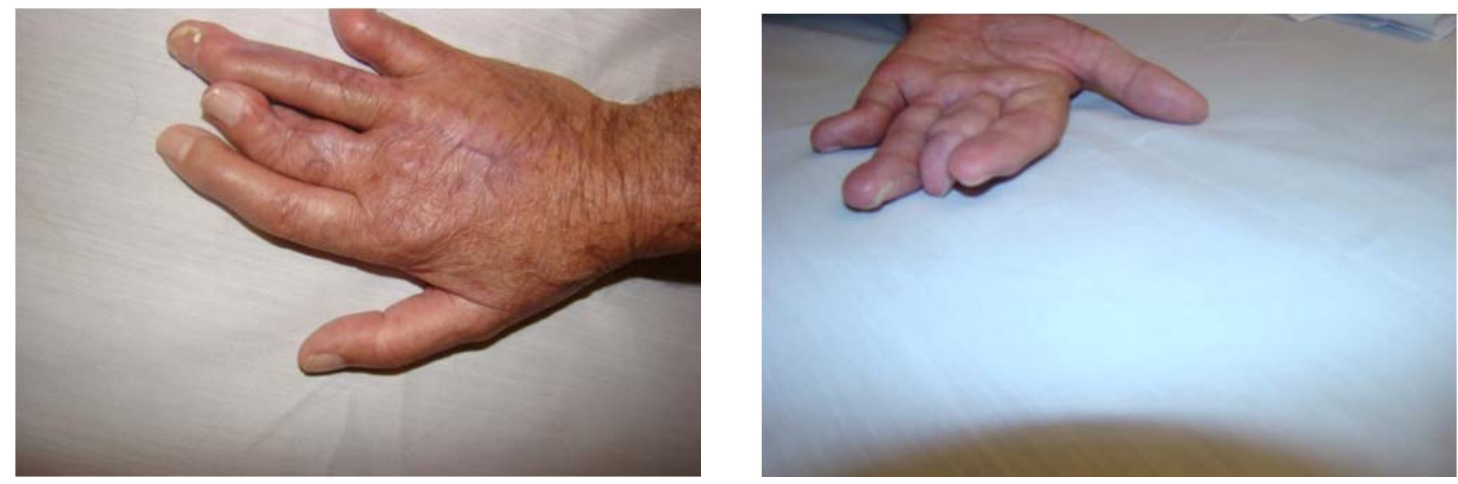

Figure 3: The patient's hands after treating by Persian medicine 


\section{Acknowledgment}

None

\section{Conflict of Interest}

The author declare that he has no conflict of interest

\section{References}

1. Di Saverio S, Tugnoli G, Catena F, Ansaloni L, Naidoo N. Trauma Surgery - Volume 1: Trauma Management, Trauma Critical Care, Orthopedic Trauma and Neuro-Trauma. Springer-Verlag Mailand. 2014.

2. Larijani B, Moghimi M, et al. Common Types of Diabetic Dosage Forms in Medieval Persia. Pharm Hist 45 (2015): 96-99.

3. Avicenna. Qanun fi al-Tib [Canon of Medicine]. Beirut: Ehyaol Toras al-Arabi Press 1 (2010): 263-264.

4. Razes. Al Havi [Liber Continent]. Beiruot: Ehyaol Toras al-Arabi Press 1: 2001.

5. Jorjani I. Zakhireye Kharazmshahi (Treasure of the Khwarazm Shah). Edited by: Ehya Teb-e-Tabiee org. Qom: Jalaleddin Press; 2011, Vol 1.

6. Kermani MK. Daqaeq-al Alaj. Edited by: Zia Ebrahimi I. Kerman: Saadat Press 1983. Vol 1. P 225.

7. Chashti MA (Nazem Jahan). Exir e Azam. Vol.3. $1^{\text {st }}$ ed. Tehran, Iran: Research Institute for Islamic and Complementary Medicine; 2008.

8. Arzani MA. Teb-e-Akbari. Edited by: Ehya Teb-e-Tabiee org. Qom: Jalaleddin Press; 2008, Vol 1.

9. Aghili Khorasani MH. Makhzan-ol-Adviyah. Edited by: Shams Ardakani MR, Rahimi R, Farjadmand F. Tehran: Tehran University of Medical Sciences; 2009.

10. Tonekaboni HM. Tohfat al momenin. Edited by: Shams Ardekani MR, Rahimi RF. Tehran: Research Center of Traditional Medicine. Shahid Beheshti University of Medical Sciences.Nashre Shahr Press; 2007.

11. Aghili Khorasani Shirazi MH. Qarabadin-e-Kabir. (lithograph in Persian); Tehran: mahmoudi Press; 1970.

12. Hosseinzadeh H, Ramezani M, Salmani G. Antinociceptive, anti-inflammatory and acute toxicity effects of Zataria multiflora Boiss extracts in mice and rats. J Ethnopharmacol 73 (2000): 379-385.

13. Shokri H, Asadi F, Bahonar AR, Khosravi AR. The Role of Zataria multiflora Essence (Iranian herb) on Innate Immunity of Animal Model. Iran J Immunol 3 (2006): 164-168.

14. Jazani NH, Ghasemnejad-Berenji H, Sadegpoor S. Antibacterial effects of Iranian Mentha pulegium essential oil on isolates of Klebsiella sp. Pak J Biol Sci 12 (2009): 183-185.

15. Rebolla A, Arisawa EA, Barja PR, Posso MB, Carvalho Cda S. Effect of Brassica oleracea in rat's skin wound healing. Acta Cir Bras 28 (2013): 664-669.

16. Deters A, Zippel J, Hellenbrand N, Pappai D, Possemeyer C, Hensel A. Aqueous extracts and polysaccharides from Marshmallow roots (Althea officinalis L.): cellular internalisation and stimulation of cell physiology of human epithelial cells in vitro. J Ethnopharmacol 127 (2010): 62-69. 
17. Rodríguez-Muela C, Rodríguez HE, Arzola C, Díaz-Plascencia D, Ramírez-Godínez JA, et al. Antioxidant activity in plasma and rumen papillae development in lambs fed fermented apple pomace. $\mathrm{J}$ Anim Sci 93 (2015): 2357-2362.

18. Feyzi R, Boskabady MH, Seyedhosseini Tamijani SM, Rafatpanah H, Rezaei SA. The Effect of Safranal on Th1/Th2 Cytokine Balance. Iran J Immunol 13 (2016): 263-273.

19. Moshiri M, Vahabzadeh M, Hosseinzadeh H. Clinical Applications of Saffron (Crocus sativus) and its Constituents: A Review. Drug Res (Stuttg) 65 (2015): 287-295.

20. Slavov A, Kiyohara H, Yamada H. Immunomodulating pectic polysaccharides from waste rose petals of Rosa damascena Mill. Int J Biol Macromol 59 (2013): 192-200.

21. Ocaña-Fuentes A, Arranz-Gutiérrez E, Señorans FJ, Reglero G. Supercritical fluid extraction of oregano (Origanum vulgare) essentials oils: anti-inflammatory properties based on cytokine response on THP-1 macrophages. Food Chem Toxicol 48 (2010): 1568-1575.

22. Oryan A, Mohammadalipour A, Moshiri A, Tabandeh MR. Topical Application of Aloe vera Accelerated Wound Healing, Modeling, and Remodeling: An Experimental Study with Significant Clinical Value. Ann Plast Surg. 2014 Jul 4.

23. Rahmani N, Khademloo M, Vosoughi K, Assadpour S. Effects of Aloe vera cream on chronic anal fissure pain, wound healing and hemorrhaging upon defection: a prospective double blind clinical trial. Eur Rev Med Pharmacol Sci 18 (2014): 1078-1084.

24. Tabandeh MR, Oryan A, Mohammadalipour A. Polysaccharides of Aloe vera induce MMP-3 and TIMP-2 gene expression during the skin wound repair of rat. Int J Biol Macromol 65 (2014): 424-430

25. Khan AW, Kotta S, Ansari SH, Sharma RK, Kumar A, Ali J. Formulation development, optimization and evaluation of aloe vera gel for wound healing. Pharmacogn Mag 9 (2013): S6-S10.

26. Shahzad MN, Ahmed N. Effectiveness of Aloe Vera gel compared with 1\% silver sulphadiazine cream as burn wound dressing in second degree burns. J Pak Med Assoc 63 (2013): 225-230.

27. Pereira GG, Guterres SS, Balducci AG, Colombo P, Sonvico F. "Polymeric Films Loaded with Vitamin E and Aloe Vera for Topical Application in the Treatment of Burn Wounds," BioMed Research International 2014.

28. Prisăcaru AI, Andriţoiu CV, Andriescu C, Hăvârneanu EC, Popa M, Motoc AG, Sava A. Evaluation of the wound-healing effect of a novel Hypericum perforatum ointment in skin injury. Rom J Morphol Embryol 54 (2013): 1053-1059.

29. Dikmen M, Oztürk Y, Sagratini G, Ricciutelli M, Vittori S, Maggi F. Evaluation of the wound healing potentials of two subspecies of Hypericum perforatum on cultured NIH3T3 fibroblasts. Phytother Res 25 (2011): 208-214.

30. Oztürk N, Korkmaz S, Oztürk Y. Wound-healing activity of St. John's Wort (Hypericum perforatum L.) on chicken embryonic fibroblasts. J Ethnopharmacol 111 (2007): 33-39.

31. Herlin C, Bertheuil N, Bekara F, Boissiere F, Sinna R, Chaput B. Leech therapy in flap salvage: Systematic review and practical recommendations. Ann Chir Plast Esthet 62 (2017): e1-e13. 
32. Durrant C, Townley WA, Ramkumar S, Khoo CT. Forgotten digital tourniquet: salvage of an ischaemic finger by application of medicinal leeches. Ann R Coll Surg Engl 88 (2006): 462-464.

Citation: Hoorieh Mohammadi Kenari, Gholamreza Kordafshari, Somayeh Aghighi, Maryam Moghimi. Treatment of A Traumatic Injury of Hand With Persian Medicine. Archives of Clinical and Biomedical Research 2 (2018): 059-067. 